\begin{tabular}{|cc|}
\hline TERPENES & EMISSION \\
FOREST & WOOD \\
FELLING & LIMBING \\
TIMBER & PULPWOOD \\
PINE & SPRUCE \\
\hline
\end{tabular}

Open access revised manuscript version of

Scandinavian Journal of Forest Research 6 (1991) 253-258

Link to publisher

\title{
Conifer monoterpenes emitted to air by logging operations
}

Ann-Margret Strömvall and Göran Petersson

Further studies of terpenes related to forestry were made for:

Terpenes in pine plantations

Terpenes emitted on barking 


\title{
Conifer Monoterpenes Emitted to Air by Logging Operations
}

\author{
Ann-Margret Strömvall and Göran Petersson \\ Department of Chemical Environmental Science \\ Chalmers University of Technology \\ 41296 Göteborg, Sweden
}

\begin{abstract}
Concentration levels in air were determined for monoterpenes emitted from forestry in south-west Sweden. Field samples were collected on Tenax cartridges and analyzed in the laboratory by techniques based on gas chromatography.
\end{abstract}

Processing of Scots pine as well as Norwegian spruce gave rise to $-1000 \mu \mathrm{g} / \mathrm{m}^{3}$ of total monoterpenes near the machine. The corresponding levels above fresh branch wood were $100-500 \mu \mathrm{g} / \mathrm{m}^{3}$. The background level was $\sim 1 \mu \mathrm{g} / \mathrm{m}^{3}$.

The major monoterpenes were $\alpha$-pinene and 3-carene from Pinus sylvestris and $\alpha$-pinene and $\beta$-pinene from Picea abies. Compounds constituting 1-10\% each of the total monoterpenes were camphene, 3 -carene, limonene, $\beta$-phellandrene and myrcene for spruce and camphene, $\beta$-pinene, limonene, $\beta$-phellandrene, myrcene and terpinolene for pine. Representative percentual compositions for the two species are given for 13 monoterpenes.

Photo-oxidant formation from the monoterpenes is discussed with respect to potential local contributions to strain and damage on forests. Possible preventive measures are suggested.

Key-words: Monoterpenes, gas chromatography, ambient air, photo-oxidants, final felling, harvesting, limbing, cross cutting, Scots pine, Norwegian spruce, forest decline 


\section{INTRODUCTION}

Presently, the importance of photo-oxidants for the wide-spread forest decline in Europe is generally recognized. It is also widely recognized that the presence and effects of photo-oxidants in forests cannot be properly understood without considering the role of terpenes. Natural terpenes from forests have been extensively studied and their impact on photo-oxidant formation has been computed (Lurmann et al.,1983).

Surprisingly, emissions of monoterpenes from forestry and the forest industry have received much less attention up till now. The present study is part of a program for the study of anthropogenic monoterpene emissions. Recently, industrial emissions from stone groundwood pulp production were reported ( Strömvall and Petersson, 1990 ). 


\section{MATERIALS AND METHODS}

Forestry. Terpene samples were taken during and after different logging operations in two pine and three spruce stands in July-September 1989. Representative results are reported from a spruce stand $25 \mathrm{~km}$ east of Göteborg and a pine stand $35 \mathrm{~km}$ north-west of Göteborg. Both stands were located 100-120 m above sea level on locally fairly plain ground. The pines were $\sim 80$ years and the spruces $\sim 90$ years old. The soils were representative for Swedish pine and spruce forests, i.e. poorer for the pine stand.

The reported samples from processing refer to the use of the same medium-sized harvester in both forest stands. The machine managed felling, limbing and cross cutting of $\sim 40$ trees per hour to timber and pulp wood. The sampling device was fastened on the machine $\sim 2 \mathrm{~m}$ from the points of limbing and cross cutting. The machine leaved logs and branch wood on the ground.

Analytical technique. Sampling of monoterpenes was accomplished by adsorption on Tenax cartridges. Accurately determined volumes of air ( $50-5000 \mathrm{ml}$ ) were passed through the cartridges by coupling them to small conventional air pumps. Duplicate or triplicate samples were taken to control the analytical quality and representativity of the results.

The monoterpenes were assessed in the laboratory by thermal desorption at $200^{\circ} \mathrm{C}$, directly combined with gas chromatography on a fused silica open tubular column. Initially, the column works as a cold trap for the desorbed monoterpenes. The stationary phase was the cross-linked methyl silicone BP-1. The oven temperature was raised $2^{\circ} \mathrm{C} \mathrm{min}^{-1}$ from $0^{\circ} \mathrm{C}$. Detection was by flame ionization and chromatograms and analytical data were obtained from reporting integrators.

Further details of the analytical method were given previously for applications to urban hydrocarbons (Mattsson and Petersson, 1982 ), monoterpenes in Scandinavian pine forests ( Petersson,1988) and monoterpenes from stone groundwood ( Strömvall and Petersson, 1990 ). 


\section{RESULTS}

Eight pine-related and more than twenty spruce-related samples were analyzed. All samples were taken under conditions with fairly weak winds. Results are given for selected samples found to be well representative with respect to concentration levels and monoterpene composition. The chromatographic separation of the monoterpenes is illustrated in Fig. 1 and quantitative data are given in Tables 1 and 2 . The results are discussed primarily with respect to total concentration levels and composition of monoterpenes.

\section{Terpene concentration levels}

The results given in Table 1 indicate concentration levels for seven major monoterpenes from Scots pine and Norwegian spruce. These compounds were found to constitute more than $95 \%$ of total hydrocarbon monoterpenes for both species.

Near the harvester, the total concentrations were higher than $1000 \mu \mathrm{g} / \mathrm{m}^{3}$ and similar for pine and spruce. The content of monoterpenes is known to be higher in pine but the number of branches cut off from the stem is much larger for spruce.

On processing young spruce, total concentrations above $1500 \mu \mathrm{g} / \mathrm{m}^{3}$ were recorded. Pine, felled a few days before processing, gave rise to levels around $500 \mu \mathrm{g} / \mathrm{m}^{3}$. These differences are probably significant but should be interpreted with some caution because different stand and weather parameters may have a marked influence.

The samples mentioned were taken a few metres from the processing points. A sample taken $\sim 50 \mathrm{~m}$ downwind from the pine harvester of Table 1 revealed a total level of $\sim 300 \mu \mathrm{g} / \mathrm{m}^{3}$. This is in accordance with lowered concentrations at an increased distance from the largest emissions.

Samples taken $\sim 1 \mathrm{~m}$ above the fresh branch wood after the spruce harvester but outside the processing plume demonstrated total monoterpene levels above $500 \mu \mathrm{g} / \mathrm{m}^{3}$. On the same occasion, the concentrations on the machine ( Table 1 ) were about twice as high. For a similar sample taken above one-day-aged branch wood (Table 1 ), the level was $\sim 200 \mu \mathrm{g} / \mathrm{m}^{3}$. This sample was taken so that influence from processing and from fresh branch wood was avoided, and the result indicates the rate of decrease of emissions with ageing. The monoterpene levels in another spruce stand, four weeks after thinning in July, were only about $10 \%$ of those given for 2 nd day branch wood. 
Table 1. Illustrative monoterpene concentration levels in air $\left(\mu \mathrm{g} / \mathrm{m}^{3}\right)$.

\begin{tabular}{lcccc}
\hline $\begin{array}{c}\text { Pine } \\
\text { harvester }\end{array}$ & $\begin{array}{c}\text { Spruce } \\
\text { harvester }\end{array}$ & $\begin{array}{c}\text { Spruce } \\
\text { branch wood, } \\
\text { 2nd day } \\
9 / 05 / 89 \mathrm{c}\end{array}$ & $\begin{array}{c}\text { Background } \\
\text { upwind } \\
\text { clear - felling } \\
9 / 05 / 89^{\mathrm{d}}\end{array}$ \\
& $7 / 28 / 89^{\mathrm{a}}$ & $9 / 05 / 89 \mathrm{~b}$ & & \\
\hline -pinene & 478 & 455 & 76.7 & 0.54 \\
camphene & 13.0 & 66.7 & 8.4 & 0.07 \\
$\beta$-pinene & 36.4 & 328 & 56.2 & 0.11 \\
myrcene & 22.7 & 71.6 & 10.8 & 0.02 \\
3-carene & 522 & 54.8 & 13.0 & 0.62 \\
$\beta$-phellandrene & 16.2 & 98.3 & 15.8 & 0.02 \\
limonene & 19.5 & 95.0 & 14.8 & 0.04 \\
& & & & \\
\hline
\end{tabular}

a $805_{-} 8^{20}, 133 \mathrm{ml}, 15^{\circ} \mathrm{C}$, on machine.

b $10^{50}-11^{15}, 177 \mathrm{ml}, 15^{\circ} \mathrm{C}$, on machine.

c 910-1300, $833 \mathrm{ml}, \sim 1 \mathrm{~m}$ above ground.

$d 9^{50}-1200,1900 \mathrm{ml}, \sim 1 \mathrm{~m}$ above ground. 
The background monoterpene levels given in Table 1 are only $\sim 0.1 \%$ of those near the harvester. The composition of monoterpenes indicates that they originate mainly from pines although the nearest forest stand consisted mainly of (lower-emitting ) spruce. The background levels recorded are similar to those reported in extensive studies in West Germany ( Jüttner, 1988 a ) and other parts of the world.

Under favourable night-time meteorological conditions in the summer season, the total monoterpene level may increase to $\sim 100 \mu \mathrm{g} / \mathrm{m}^{3}$ in certain Swedish pine forests ( Petersson, 1988 ). Under such conditions, the concentration levels resulting from logging operations and fresh branch wood should be much higher than those reported in the present study.

\section{Composition of monoterpenes}

In Table 2, a comprehensive list of percentual composition of monoterpenes is given for the two conifer species studied. The selected samples corresponding to tree processing were found to give well representative results. The retention data given aid in the identification of the minor monoterpenes.

Norwegian spruce. The two major monoterpenes from spruce were $\alpha$-pinene and $\beta$-pinene. Samples reflecting emissions from processing and fresh branch wood of young spruce revealed about equal concentrations of the two compounds. Old spruce gave rise to a larger ratio with up to twice as much $\alpha$-pinene as $\beta$-pinene. This may be explained by a larger portion of monoterpenes from wood and sawdust compared to cortical monoterpenes. The ratio was shown to be larger than 2 in the plume from grinding of spruce wood ( Strömvall and Petersson, 1990 ).

An increased proportion of monoterpenes from broken needles should also increase the ratio because $\alpha$-pinene and camphene are the major monoterpenes in spruce needles whereas the content of $\beta$-pinene is low ( Jüttner, $1988 \mathrm{~b}$ ). The portion of camphene in the present study varied between different samples but did not exceed $10 \%$. It is concluded that the monoterpene pool of the spruce needles contributes less than other monoterpene pools.

Limonene, $\beta$-phellandrene, myrcene and 3-carene were the four other prominent monoterpenes from spruce. The percentage of myrcene and $\beta$-phellandrene is much higher than in the emissions from wood grinding, indicating that they originate mainly from the cortical pool. 
Table 2. Percentual composition and physical data of ambient monoterpenes from conifer harvesting.

\begin{tabular}{|c|c|c|}
\hline $\begin{array}{c}\text { Retention }^{\mathrm{a}} \\
\text { in GC } \\
\mathrm{MU}\end{array}$ & $\begin{array}{c}\text { Spruceb }^{b} \\
\text { harvester } \\
\%\end{array}$ & $\begin{array}{c}\text { Pine }^{\mathrm{c}} \\
\text { harvester } \\
\%\end{array}$ \\
\hline
\end{tabular}

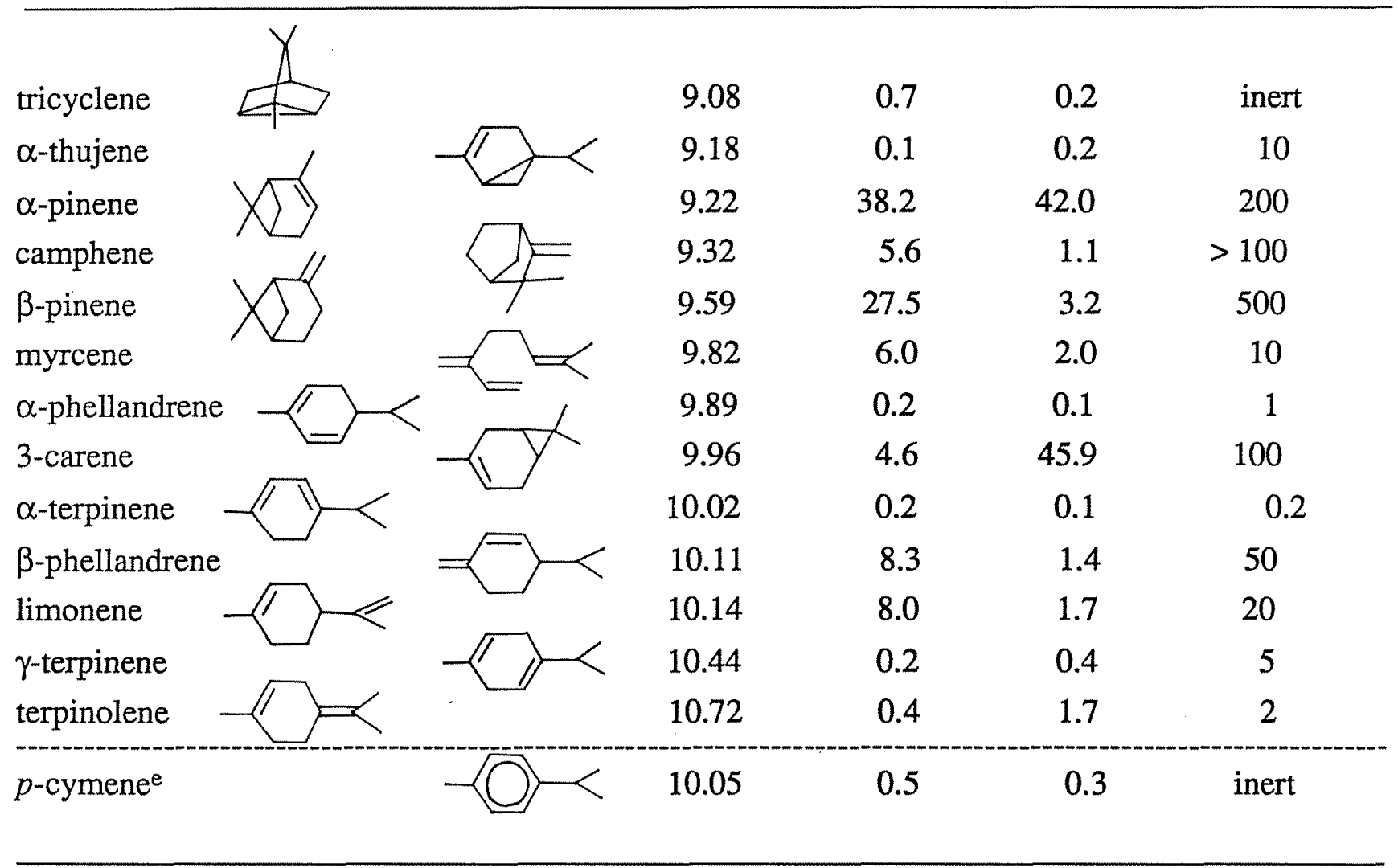

a Retention times in methylene units ( $M U$ ) linearly interpolated between nonane (9.00), decane (10.00) and undecane $(11.00)$.

$\mathrm{b}$ Picea abies, 9/05/89, 1050-1115.

c Pinus sylvestris, $7 / 28 / 89,8^{05}-820$.

d Approximate lifetime in air with $50 \mathrm{ppb}$ of ozone.

e Monoterpene-related alkylbenzene. 
Scots pine. $\alpha$-Pinene and 3-carene were predominant in all pine samples. The content of 3-carene was $0-20 \%$ higher than that of $\alpha$-pinene in three harvester plume samples taken in the same morning and at the same location as the tabulated sample. Samples from another locality taken during the processing of pines, felled a few days earlier by power saw, exhibited $10-20 \%$ less 3-carene than $\alpha$-pinene. The content of 3-carene in Scots pine is known to be very variable ( Yazdani and Nilsson, 1986) which should influence its presence in air. Nitrogen fertilization increases the proportion of 3-carene in Scots pine ( Hiltunen et al., 1975). Predominance of $\alpha$-pinene and 3-carene in variable ratios was previously observed in the air of intact Swedish planted pine stands as well (Petersson, 1988 ).

The chromatogram in Fig. 1 visualizes the separation and the quantitative ratios of the monoterpenes from pine. Among the less prominent components, the high content of terpinolene characterizes pine compared to spruce. The composition of these monoterpenes is similar to that reported for stem phloem of Scots pine in Finland (Hiltunen et al., 1975 ).

The chromatogram also illustrates the presence of diesel oil and exhaust hydrocarbons from the harvester. The $\mathrm{C}_{10}-\mathrm{C}_{12} n$-alkanes were the most prominent diesel components, each amounting to $\sim 1 \%$ of the total monoterpene concentration. Most other samples from working logging machines exhibited lower relative amounts of diesel hydrocarbons. 


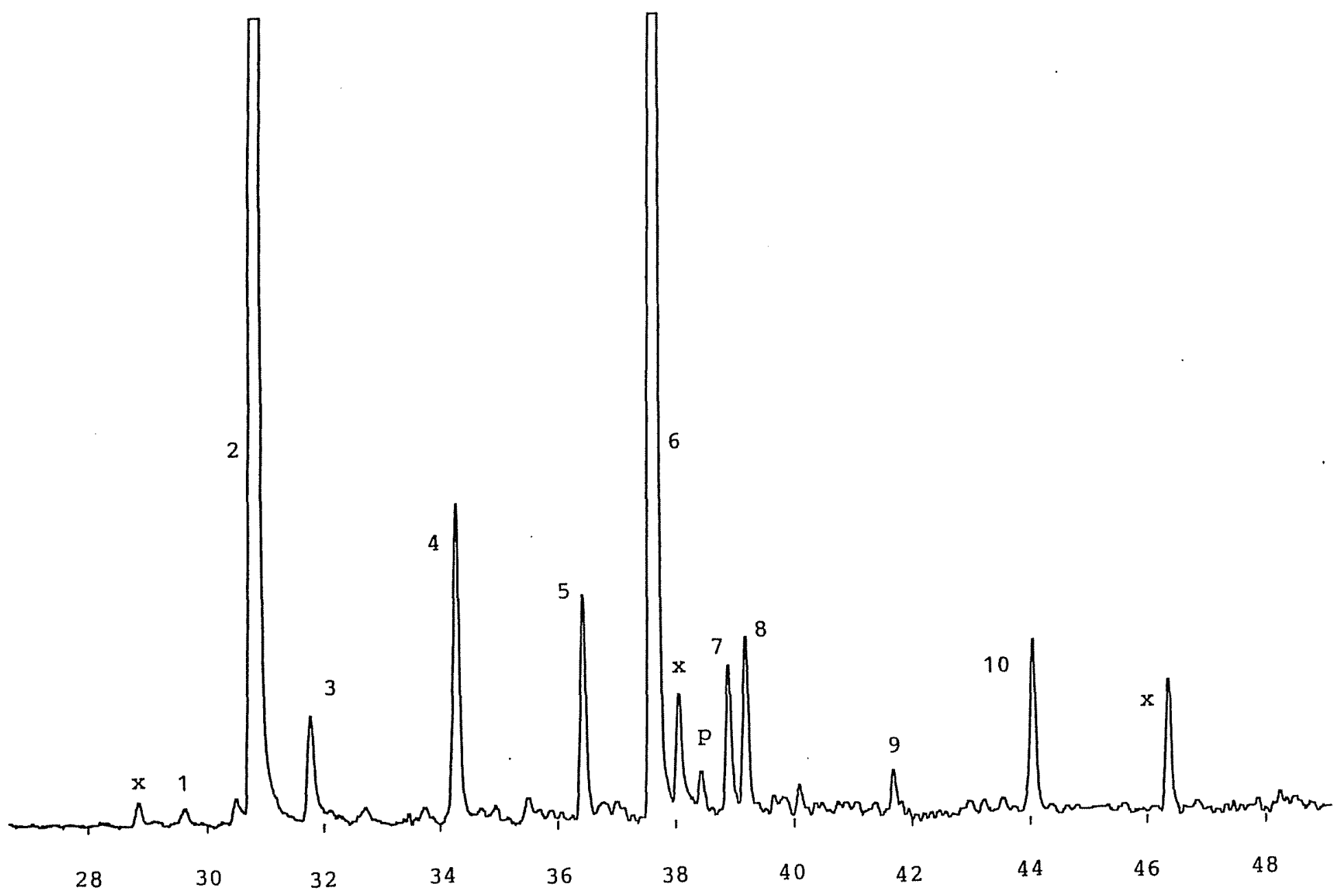

Fig. 1. Gas chromatographic separation of monoterpenes in the air during processing of Scots pine, 7/28/89. ( 1 tricyclene; $2 \alpha$-pinene; 3 camphene; $4 \beta$-pinene; 5 myrcene; 63 -carene; $7 \beta$-phellandrene; 8 limonene; $9 \gamma$-terpinene; 10 terpinolene; $\mathrm{p} p$-cymene; $\mathrm{x}$ nonane, decane and undecane from diesel oil and exhaust ) 


\section{DISCUSSION}

The composition and concentration levels of monoterpenes from forestry are likely to be fundamental in efforts to understand interrelations between forests and anthropogenic and biogenic hydrocarbons in air.

\section{Photo-oxidant aspects}

The unsaturated monoterpenes react rapidly with ozone at very different rates. The approximate lifetimes given in Table 2 were estimated from literature data ( Atkinson and Carter, 1984 ). The lifetimes of some of the slow-reacting monoterpenes may be shortened further by the competing reaction with $\mathrm{OH}$ radicals. During severe photo-oxidant episodes, the ozone levels are often higher than $50 \mathrm{ppb}$ resulting in correspondingly shorter lifetimes for the monoterpenes.

The reactions between monoterpenes and ozone initially lower ozone levels. By analogy with alkenes like propene and butenes, net formation of ozone from monoterpenes may follow under conditions favouring photo-oxidant formation. In the monoterpene plume from conifer processing, nitrogen oxides required for efficient ozone formation are provided by the diesel engine. The ozonolysis of the monoterpenes also gives rise to immediate formation of radicals, aldehydes and other potentially harmful photo-oxidants.

The monoterpenes differ from most urban and industrial anthropogenic hydrocarbons by the very rapid conversion to photo-oxidants. As a consequence, enhanced photo-oxidant levels and resulting harmful effects on forests during oxidant episodes are expected to occur within short distances, in the $\mathrm{km}$ range, from the locations of logging operations.

\section{Impact on forestry}

The magnitude of the contribution of monoterpenes from forestry to photo-oxidant formation and forest strain and damage will probably be much studied in the near future. Before the answers are fully known, it is important to recognize that potential ecological and economical losses can be prevented in different ways. An efficient means of preventing or lowering photo-oxidant formation is the planning of logging operations in time. In northern Europe, the autumn and winter seasons are favourable 
because of low photochemical activity. Sunny periods during spring and summer are unfavourable. Logging operations in the morning hours may then give rise to particularly high photo-oxidant levels later in the day.

The use of logging machines with combustion engines is unfavourable because the large monoterpene emissions are co-emitted with nitrogen oxides from the engines. These logging operations should be of particular interest to regulate with respect to the time of the year and the day. Reducing the terpene-bleeding surfaces formed in logging should also be essential. Lowered emissions of nitrogen oxides from the logging machines is another obviously important point.

\section{ACKNOWLEDGEMENTS}

The studies were performed in the forests of and with the kind assistance of "Skogssällskapet" and its woodsmen.

The authors are grateful to the Swedish Council for Forestry and Agricultural Research for prompt financial support. 


\section{REFERENCES}

Atkinson, R. and Carter, P.L. 1984. Kinetics and mechanisms of the gas-phase reactions of ozone with organic compounds under atmospheric conditions. Chem. Rev. 84, 437-470.

Hiltunen, R., Schantz, M. and Löyttyniemi, K. 1975. The effect of nitrogen fertilization on the composition and the quantity of volatile oil in Scots pine. Commun. Inst. For. Fenn. 85, 1-14.

Jüttner, F. 1988 a. Quantitative analysis of monoterpenes and volatile organic pollution products ( VOC) in forest air of the southern Black Forest. Chemosphere 17, 309-317.

Jüttner, F. 1988 b. Changes of monoterpene concentrations in needles of pollution-injured Picea abies exhibiting montane yellowing. Physiol. Plant. 72, 48-56.

Lurmann, F.W., Lloyd, A.C. and Nitta, B. 1983. Modeling potential ozone impacts from natural hydrocarbons - II. Hypothetical biogenic HC emission scenario modeling. Atmospheric environment 1983, 1951-1963.

Mattsson, M. and Petersson, G. 1982. Trace analysis of hydrocarbons in air using standard gas chromatographic and personal sampling equipment. Intern. J. Environ. Anal. Chem. 11, 211-219.

Petersson, G. 1988. High ambient concentrations of monoterpenes in a Scandinavian pine forest, Atmospheric Environment 22, 2617-2619.

Strömvall, A.-M. and Petersson, G. 1990. Ambient monoterpenes from stone groundwood pulp production. Holzforschung, to be published.

Yazdani, R. and Nilsson, J.-E.1986. Cortical monoterpene variation in natural populations of Pinus sylvestris in Sweden. Scand. J. For. Res. 1, 85-93. 